\title{
Vitreloy-105 Behavior Under Mutual Wear
}

\author{
Felipe Raphael Salgado * (D), Janaina Fracaro de Souza Gonçalves ${ }^{a}$, Marcio Andreato Batista Mendes ${ }^{b}$, \\ Nelson Delfino de Campos Neto ${ }^{c, d}$ (D), Marcelo Falcão de Oliveira ${ }^{c}$ \\ ${ }^{a}$ Universidade Tecnológica Federal do Paraná, Departamento de Engenharia Mecânica, Londrina, PR, Brasil \\ ${ }^{b}$ Universidade Tecnológica Federal do Paraná, Departamento de Engenharia de Materiais, Londrina, PR, Brasil \\ ${ }^{c}$ Universidade de São Paulo, Departamento de Engenharia de Materiais, São Carlos, SP, Brasil \\ ${ }^{d}$ Colorado School of Mines, George S. Ansell Department of Metallurgical and Materials Engineering, \\ Golden, CO, USA
}

Received: January 15, 2020; Revised: June 24, 2020; Accepted: June 26, 2020

\begin{abstract}
Zr-based bulk metallic glasses (BMGs) are widely used as mechanical components due to their excellent properties and high glass-forming ability. However, there is a lack of research concerning the tribological behavior of BMG versus BMG. The sliding characteristics of Vitreloy-105 $\left(\mathrm{Zr}_{52.2} \mathrm{Cu}_{17.9} \mathrm{Ni}_{14.6} \mathrm{Al}_{10} \mathrm{Ti}_{5}\right.$ at.\%) were studied in air using a pin-on-disk apparatus equipped for continuous measurement of friction force and without lubrication. The counterface material was the same BMG. The structure, thermal stability, and wear morphology were examined by X-ray diffraction, differential scanning calorimetry, non-contact profilometer, and scanning electron microscopy. For a normal load applied (10.0, 20.4 and 38.2 N) at constant $233 \mathrm{rpm}$ the coefficient of friction ranged from 0.30 to 0.36 at steady state. Average wear rate was more pronounced on the pins under higher load and the predominant wear mechanism observed was adhesive, with presence of peeling-off and micro-cracks accompanied by some grooves and abrasive wear at lower loads.
\end{abstract}

Keywords: Zr-based bulk metallic glasses, tribological properties, wear resistance.

\section{Introduction}

BMGs are metastable materials produced at cooling rates above the critical cooling rate necessary to avoid the nucleation of crystals. The lack of long-range atomic order can provide properties to amorphous alloys better than in conventional crystalline ones ${ }^{1}$. These materials have been emerging due to their excellent combination of mechanical properties. In general, they present low modulus of elasticity ${ }^{2}$, high hardness ${ }^{3}$, and high strength ${ }^{4}$. The absence of grain boundaries also provides high corrosion resistance ${ }^{5,6}$, and wear resistance ${ }^{7,8}$. Due to these properties, many researchers have been studying BMGs for improvements or new applications in several areas, such as structural materials ${ }^{9}$, sports applications ${ }^{10}$, biomaterials ${ }^{11}$, robotics, and aerospace industry $^{12,13}$.

In scientific view, the tribological properties of BMGs guide these materials to high performance applications. However, some points still need to be better understood. As the tribological properties of these materials vary for each alloy family, they cannot be generalized, which means that there is a large field to be explored ${ }^{14}$. Wear tests performed on a pin-on-disk tribometer using a Zr-based alloy and 52100 steel counterparts have shown that their performance is different in dry and lubricated conditions ${ }^{15}$. Another study using a Zr-based BMG and AISI 8660 counterpart showed that lower normal loads and higher sliding speeds always led to higher friction coefficients under lubrication conditions ${ }^{16}$.

*e-mail: fr.salgado2@gmail.com
The mechanisms of wear in these alloys are not yet fully understood and concomitant participation of more than one mechanism is noticed most of the times. Many BMGs normally present brittle failure ${ }^{17}$, and for those BMGs the main wear mechanism is abrasive with the formation of scratches in the worn region. However, adhesion mechanisms are commonly observed during wear tests when the load is increased, confirmed by the presence of plastic deformation and by the occurrence of peel-off in some regions ${ }^{18,19}$.

Another point to highlight is the possibility of crystallization of the amorphous material induced by wearing. There was an evidence of surface crystallization induced by friction during the wear test between an amorphous $\mathrm{Zr}$-based alloy and EN 26 steel $^{20}$, where heat was caused by friction and it could change the tribological properties of the material, generating crystal nanoparticles when the material passed through the glass transition temperature $\left(\mathrm{T}_{\mathrm{g}}\right)$. On the other hand, reports of another study showed that microhardness tests carried out after wear tests between a Zr-based alloy and AISI 8660 steel presented good thermal stability and that there was no induced crystallization on the samples ${ }^{21}$.

Despite the wear issues that deserve to be better explored in the universe of BMGs, good results have been achieved with a family of Zr-based alloys known as Vitreloy. These materials present high strength at low temperatures ${ }^{22}$, excellent resilience, and high glass-forming ability ${ }^{23}$. Some of the Vitreloy alloys are promising materials for the manufacturing of micro gears for the aerospace industry ${ }^{12,13}$, for example. Precision gear systems for space applications and advanced 
robotics are known as Strain Wave Gears (SWG). This kind of gears often require specially manufactured components with specialized performance characteristics and desirable properties like low mass, small envelope, high torque capacity, precision positioning, wide operation temperature range, and vacuum operation ${ }^{13}$. These characteristics led to solutions for satellite actuators, aircraft, ground support, and tracking devices for both military and commercial applications ${ }^{24}$.

Some studies have presented good results on the wear resistance of Vitreloy alloys when rubbed against other materials ${ }^{17,25,26}$. Despite its commercial importance, there is a lack of studies evaluating the mutual wear between pairs produced with these alloys, such as that occurring between SWG teeth.

The Vitreloy-105 (Vit-105) alloy was chosen from the Vitreloy family to be used in this work due to the absence of Beryllium in its composition, considering that this chemical element is toxic and requires special manipulation in a controlled environment ${ }^{27}$. This study aimed to evaluate the mutual wear between pairs of Vit-105 to understand the main wear mechanisms involved and the possible structural changes that can occur in the material due to changes in temperature and tension strength caused by the tribosystem. Thus, there is a contribution to extend some practical applications of this alloy in systems involving friction and wear.

\section{Materials and Methods}

\subsection{Design of experiment}

The completely randomized design is used for studying the effects of one controlled factor without considering other variables. This method was chosen because it is a simple experiment from the statistical point of view, where treatments of only one factor are compared and the others remain constant. Treatment means any method, element, or material which the effect has to be measured and compared. In this work, the treatment can be defined as the wear test of Vit-105 alloy, where the controlled factor is the load, with three levels of variation. The other factors, such as source and homogeneity of the material, ambient temperature, ambient humidity, lubrication (dry), speed of rotation, and test time were kept constant. Five tests were carried out for each different load.

\subsection{Samples preparation}

A commercial $19 \mathrm{~mm}$ rod of Vit-105 was purchased from Materion in crystalline form and sectioned in pieces of around $10 \mathrm{~g}$ and $30 \mathrm{~g}$. The pieces were remelted by electric arc melting in a vacuum back-filled argon 5.0 atmosphere, then it was suction casted into water-cooled $\mathrm{Cu}$ molds using the $30 \mathrm{~g}$ pieces to produce plates ( $2 \mathrm{~mm}$ thickness) and the $10 \mathrm{~g}$ pieces to spherical-end cylinders ( $3 \mathrm{~mm}$ diameter) shapes to be used as a counterpart, and pin, respectively. X-ray diffraction (XRD) using a Bruker D8 Advance ECO equipment and differential scanning calorimetry (DSC) using a Netszch DSC 404 at $40 \mathrm{~K} / \mathrm{s}$ heating rate were used to confirm the amorphous structure of the parts, and the Vit-105 thermal parameters $\left(\mathrm{T}_{\mathrm{g}}\right.$ and $\left.\mathrm{T}_{\mathrm{x}}\right)$. The contact surfaces of pins and plates were grounded with abrasive paper (grit 1200) to attend the tribological test standard ASTM G99-0 $05^{28}$, which requires average roughness $\left(R_{a}\right)$ below $0.8 \mu \mathrm{m}$. The $R_{a}$ of plates and pins surfaces were measured using a non-contact profilometer Cyber CT 100. Three measurements were made on plates (one in the central region and two on the opposite sides of the same surface) and one measurement on the central spherical surface of the pins (in the contact point). The specimens were cleaned with alcohol and acetone, and finally weighted by using an analytical scale with $\pm 0.01 \mathrm{mg}$ accuracy. The microhardness of the surfaces was measured by Vickers hardness tester Future-Tech FM-800 under a $300 \mathrm{~g}$ load by $5 \mathrm{~s}$ at room temperature before and after the wear test. Three points on the surface of the BMG plates and pins were randomly chosen to determine the microhardness before, and other three measures were done on the plates wear track, and near to the pins worn surfaces after the test.

\subsection{Wear tests}

The wear tests were conducted using a non-commercial equipment developed and validated by the researchers (Figure 1A), in air and at room temperature. A Fluke infrared pyrometer sensor was used to measure the temperature near to the contact point between pin and plate. The applied vertical normal loads used on the pin were $38.2 \mathrm{~N}, 20.4 \mathrm{~N}$, and $10.0 \mathrm{~N}$, respectively. The rotational sliding velocity was selected to be $233 \mathrm{rpm}$ for all tests with $10 \mathrm{~mm}$ rotational radius, i.e. $0,24 \mathrm{~m} / \mathrm{s}$. The sliding distance was $800 \mathrm{~m}$. After every 200 meters the mass loss of each specimen was measured, and the specimen (Figure 1B) was cleaned with alcohol and acetone before continuing the test.

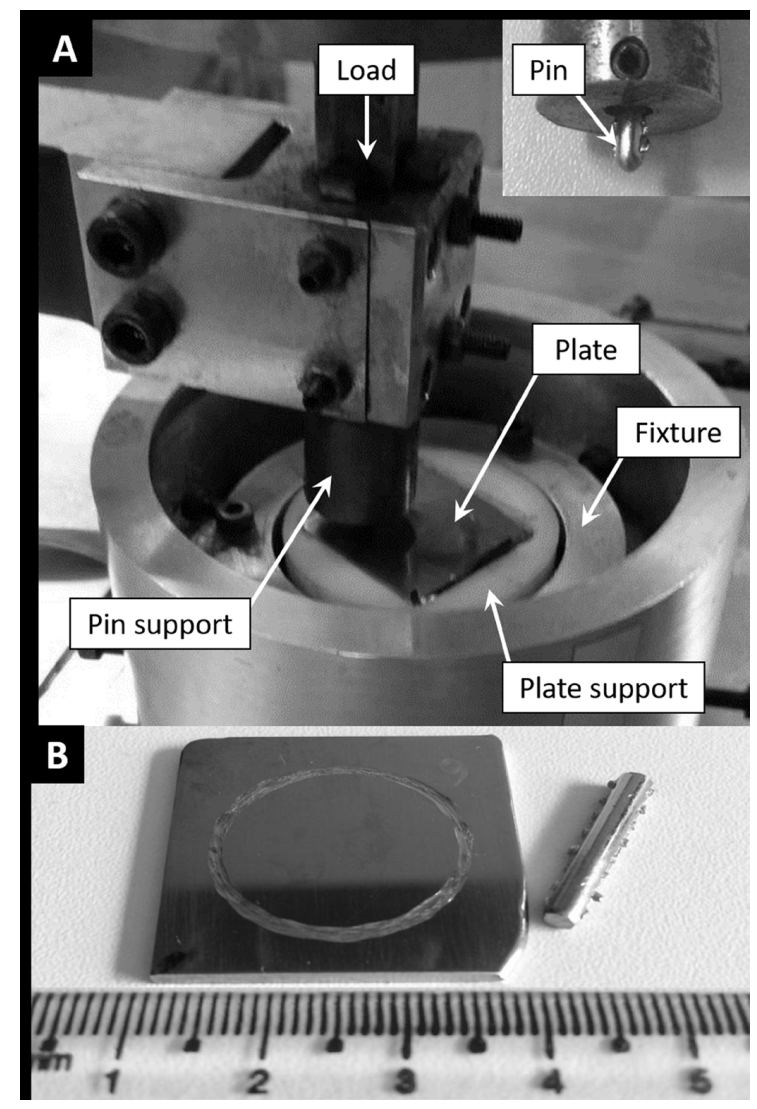

Figure 1. Pin-on-disk wear test equipment and the detail of the pin and its support on the upper right side (A). Plate and pin after the wear test (B). The ruler scale is in $\mathrm{cm}$. 


\subsection{Characterization}

Coefficient of friction (COF) and wear mass loss were obtained by calculating the average values of five samples tested at the same load. The average width of the wear tracks on the plates and diameter of the pin scars were measured using the profilometer Cyber CT 100 camera. Three measures were taken in each sample. Scanning electron microscopy (SEM) images were made to characterize the worn surfaces using a FEI Inspect S50 set to the following parameters common to all images: $\mathrm{HV}=25 \mathrm{kV}$; Detector $=\mathrm{ETD}$ (secondary electrons image); Spot $=5.0$; High Vacuum Mode. DSC was performed prior to testing to ensure that heating during testing was not sufficient to increase the temperature high enough to induce crystallization. XRD after tribological tests were carried out using a Bruker D8 Advance ECO equipment with Cu radiation coupled with a high-speed detector SSD160 to verify if there was crystallization induced by heating and/or mechanical deformation on the samples. For the XRD measurements, an adhesive tape (that does not show crystalline peaks in XRD analysis) was used to isolate the surface of the worn region from the surrounding plate.

\section{Results and Discussion}

Figure 2 presents the thermograms of the as-cast Vitreloy-105 pin before performing the wear tests. The arrows indicate the glass transition temperature $(\mathrm{Tg})$ and the crystallization temperature (Tx), confirming that amorphous structure was formed, similar to previous findings for this alloy fully amorphous ${ }^{29}$. The temperature near the pin-disk contact was measured during the tests using an infrared radiation thermometer, reaching a maximum value of $\sim 60{ }^{\circ} \mathrm{C}$. This temperature reached is below the $\operatorname{Tx}\left(451{ }^{\circ} \mathrm{C}\right)$ and it is not enough to provide localized crystallization. So, it can be deduced that there was no crystallization in the material during the tests.

XRD patterns obtained after wear tests on Vit- 105 plates are without any visible Bragg peaks, suggesting the structure of the alloy is amorphous after casting, and there was no crystallization induced by neither plastic deformation and/or heating, which is consistent with the results reported elsewhere ${ }^{17}$. Figure 3 shows the XRD patterns for the three samples (plates wear track) after wear test.

The average Vickers microhardness found for pins and plates are $510 \pm 6$ and $517 \pm 5 \mathrm{HV}$, respectively. Liu et. al. showed that the hardness of this alloy varies according to the content of crystalline phases ${ }^{17}$, and the values are similar to the presented by them when this alloy is fully amorphous. The same behavior was observed regarding hardness for BMG plates when rubbed against the same material is tested in air as mentioned by Fu and Rigney ${ }^{30}$.

The average roughness obtained at the three regions on the plates (P1 - central, P2 and P3 - opposite sides) and one point on the pins spherical surfaces (P4) before the tests are shown in Table 1. The roughness of the samples before the wear tests presented values below that established by the standard. The higher $\mathrm{R}_{\mathrm{a}}$ of the pins surface before the test can be explained by the higher difficulty in preparing a spherical surface by grinding and polishing than a flat surface such as those of the plates.

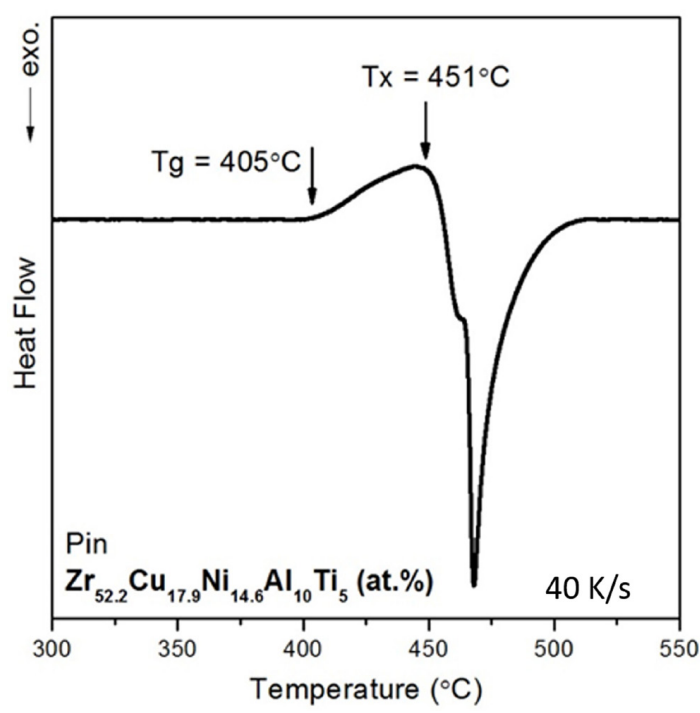

Figure 2. DSC curve for as-cast Vitreloy-105 pin.

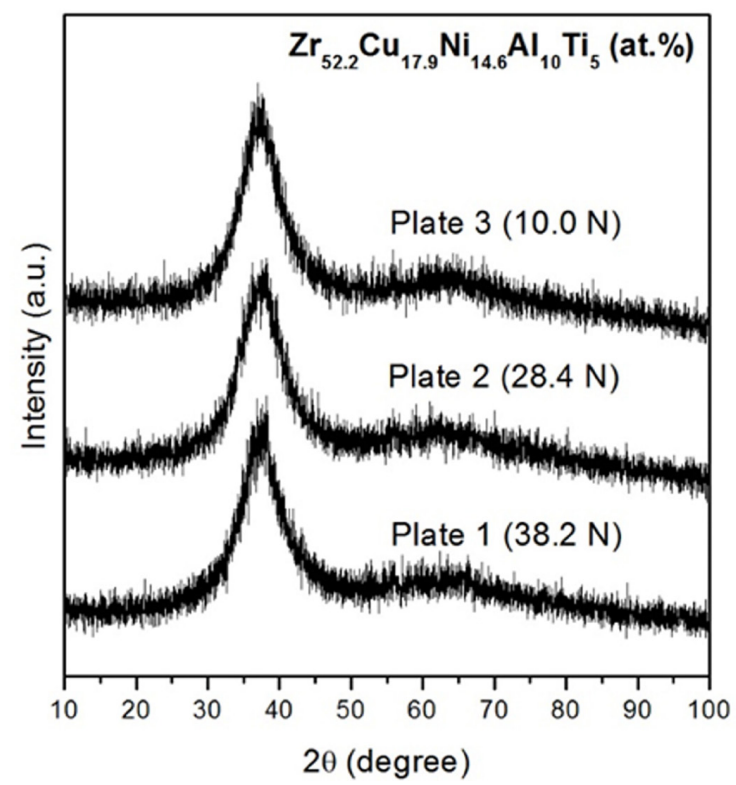

Figure 3. XRD patterns of three Vitreloy-105 plates (wear track) after wear tests, one for each applied load.

Table 1. Average plate and pins $\mathrm{R}_{\mathrm{a}}$ before wear test of Vitreloy-105.

\begin{tabular}{cccc}
\hline & Point & & $\mathrm{R}_{\mathrm{a}}(\mu \mathrm{m})$ \\
\hline \multirow{3}{*}{ Plate } & P1 & $0.22 \pm 0.05$ \\
\cline { 2 - 3 } & P2 & $0.35 \pm 0.09$ \\
\cline { 2 - 3 } & P3 & $0.29 \pm 0.06$ \\
\hline Pins & P4 & $0.63 \pm 0.10$ \\
\hline
\end{tabular}

Table 2 shows both the average COF recorded for each test disregarding the running in state (first $100 \mathrm{~m}$ ), and the overall average COF, which was in the range of $0.30-0.36$. Parlar et. al. ${ }^{21}$ used a block-on-ring apparatus to determine the COF of Vitreloy-1 (Vit-1) against an AISI 8660 ring. 
Table 2. COF values for each test according to the applied loads.

\begin{tabular}{cccc}
\hline & Load 10.0 N & Load 20.4 N & Load 38.2 N \\
\hline Test 1 & $0.368 \pm 0.020$ & $0.322 \pm 0.015$ & $0.299 \pm 0.016$ \\
\hline Test 2 & $0.372 \pm 0.017$ & $0.319 \pm 0.012$ & $0.304 \pm 0.013$ \\
\hline Test 3 & $0.363 \pm 0.016$ & $0.315 \pm 0.015$ & $0.308 \pm 0.012$ \\
\hline Test 4 & $0.369 \pm 0.020$ & $0.325 \pm 0.018$ & $0.305 \pm 0.013$ \\
\hline Test 5 & $0.354 \pm 0.016$ & $0.317 \pm 0.015$ & $0.311 \pm 0.013$ \\
\hline Average & $0.365 \pm 0.006$ & $0.320 \pm 0.004$ & $0.305 \pm 0.004$ \\
\hline
\end{tabular}

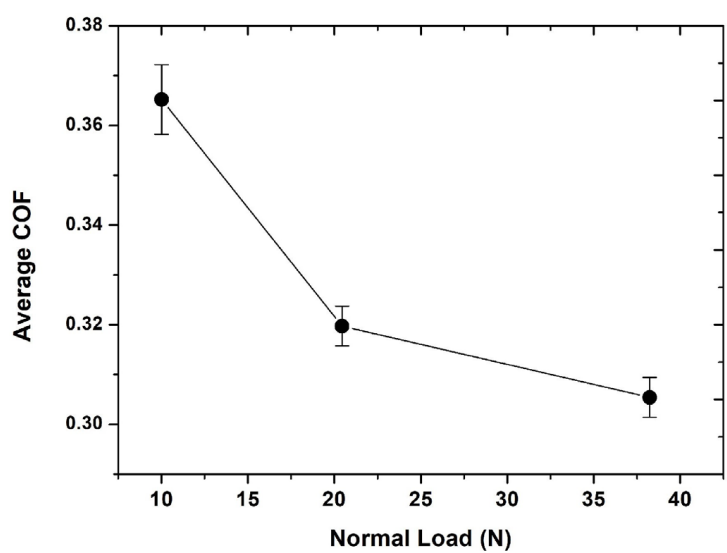

Figure 4. Average coefficient of friction for three different applied loads.

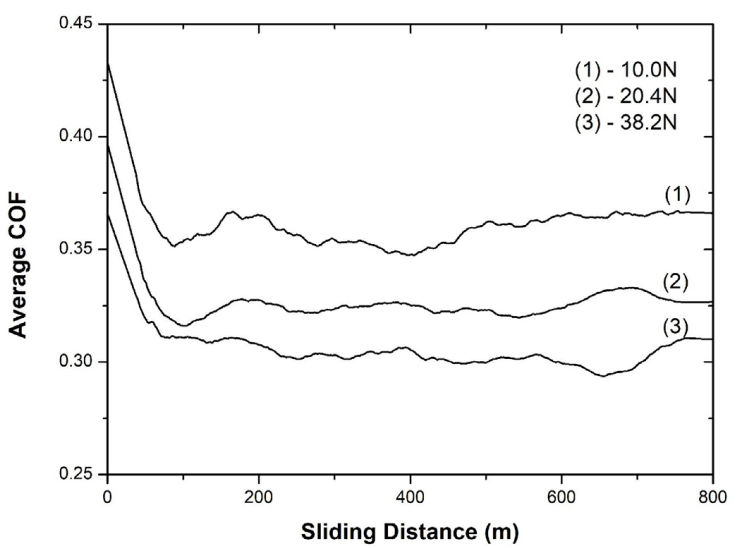

Figure 5. Development of the average COF as function of sliding distance (smoothed curves) for each applied load.

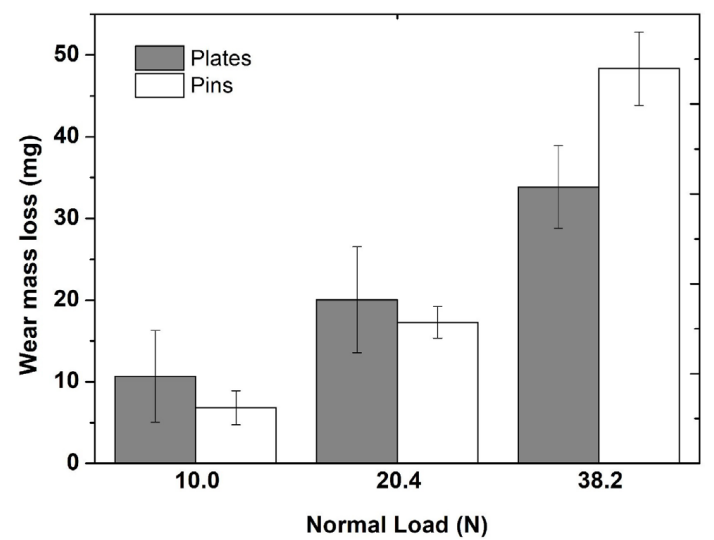

Figure 6. Average wear mass loss for plates and pins according to applied loads.
For a $0.30 \mathrm{~m} / \mathrm{s}$ sliding speed and loads of 10, 20 and $40 \mathrm{~N}$, the average COF values was in the range of $0.40-0.50^{21}$. Although the apparatus and counterpart are different from those used in this study, the COF was not much different, considering that the loads and sliding speed were similar. In Zhong et. al. work ${ }^{31}$, mutual wear test of Vit-1 was performed using a pin-on-disk tribometer and the average COF was in the range of $0.15-0.20$, but the loads applied was relatively higher $(100,125$ and $150 \mathrm{~N})$, what possibly explain the lower COF values.

Fu et. al. ${ }^{32}$, when studying wear between Zr-based BMG parts using a pin-on-disk apparatus in air, reported a COF of almost 0.4 under $10.0 \mathrm{~N}$ load, which is very close to the result achieved here under the same load. In the same study, a pin of 52100 bearing steel was rubbed against a Zr-based disk under the same conditions and presented practically the same COF. Figure 4 shows that the COF does not change much at $38.2 \mathrm{~N}$ and $20.4 \mathrm{~N}$ loads, but it increases when the load decreases to $10.0 \mathrm{~N}$. The standard deviation bars exhibit that the friction values varying more in lower normal loads than in higher ones. A similar behavior was noticed after wear tests between Vit-105 and Cr-12 steel as already reported ${ }^{17}$. The average results for the five tests conducted for each load presented a stable frictional behavior with some fluctuations especially in the beginning (running in) where COF decreases until reach the steady state, in average after $100 \mathrm{~m}$ sliding distance, as shown in Figure 5.

Figure 6 shows that the average mass loss increases with increasing normal load probably because of the higher strength on the surface caused by the higher load applied ${ }^{31}$. This behavior is in agreement with Raibinowicz ${ }^{33}$ wear volume loss relation, $\mathrm{V}=\mathrm{kPL} / \mathrm{H}$, where $\mathrm{V}$ is the volume loss, $\mathrm{k}$ is the proportional coefficient, $\mathrm{P}$ is the applied load, $\mathrm{L}$ is the sliding distance and $\mathrm{H}$ is the hardness. Both the equation and the results show that the volume loss is directly proportional to the load applied. On the other hand, there is a disagreement with Parlar et al. ${ }^{21}$, who reported that the mass loss decreases with increasing normal load.

Mass loss increases from $10.0 \mathrm{~N}$ to $20.4 \mathrm{~N}$ load for both pins and plates, but it increases significantly at $38.2 \mathrm{~N}$ especially for the pins. These results may be explained by the heat generated by the friction between plate and pin which decreases the toughness and changes the wear behavior ${ }^{31}$. Someway the pins could have concentrated more heat, becoming less hard and consequently less wear resistant. Thus, the pin surface could be easily worn out and some of its material may be transferred to the plates by the adhesion mechanism. However, there is a divergence with the results presented by Zhong et. al. ${ }^{25}$, where the plates exhibited higher mass loss than the pins (both made with Vit-1). They showed that for a load of $100 \mathrm{~N}$ the average mass loss for the disks was $16 \mathrm{mg}$ and for the pins it was $5 \mathrm{mg}$, what can be explained by the small size of the pins which dissipates the heat better than the plates and could keep the higher hardness. Comparing with the results obtained in this study, using a load five times smaller $(20 \mathrm{~N})$, the average mass loss in the plates and pins was approximately $20 \mathrm{mg}$.

The wear rate of a material $(\mathrm{Q}=\mathrm{V} / \mathrm{S})$ is a relation between the volume loss (V) and the sliding distance $(\mathrm{S})^{34}$. Figure 7 presents the average wear rate results for both plates 


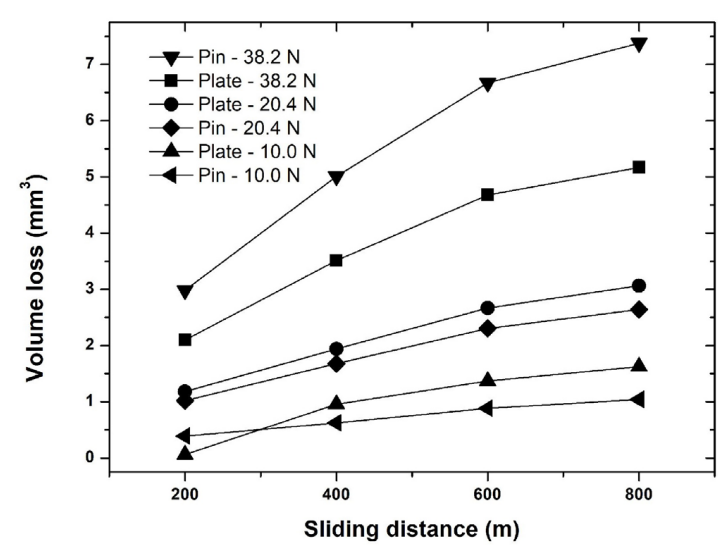

Figure 7. Volume loss vs sliding distance for plates and pins.

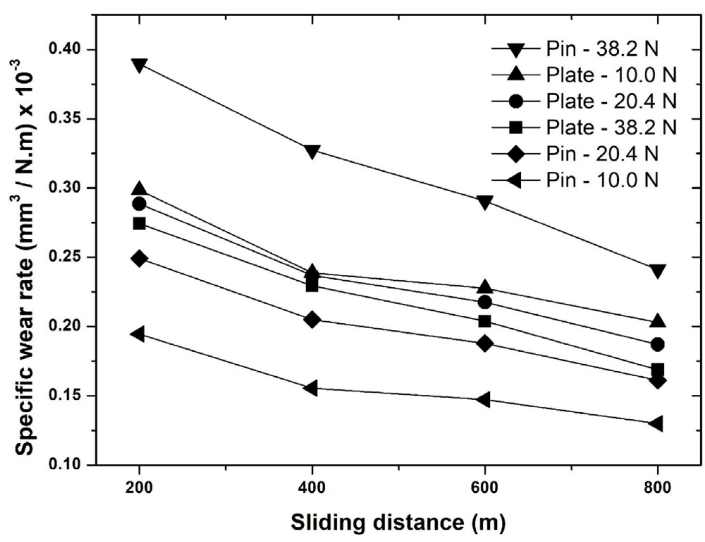

Figure 8. Specific wear rate vs sliding distance for plates and pins

Table 3. Average wear track width and pins scar diameter for each applied load.

\begin{tabular}{cccc}
\hline & Load $10.0 \mathrm{~N}$ & Load $20.4 \mathrm{~N}$ & Load 38.2 N \\
\hline $\begin{array}{c}\text { Wear track } \\
\text { width }(\mathbf{m m})\end{array}$ & $1.79 \pm 0.07$ & $2.22 \pm 0.08$ & $3.07 \pm 0.02$ \\
\hline$\Delta \mathrm{d}(\mathrm{mm})$ & $1.70 \pm 0.02$ & $2.06 \pm 0.02$ & $3.00 \pm 0.00$ \\
\hline$\Delta \mathrm{d} / \mathrm{D}$ & $0.57 \pm 0.01$ & $0.69 \pm 0.01$ & $1.00 \pm 0.00$ \\
\hline
\end{tabular}

and pins under the three different loads at room temperature. According to Geer et. al. ${ }^{35}$, there is not a linear variation of $\mathrm{V}$ with $\mathrm{S}$ in the mutual dry sliding wear of some BMGs, and there is generally a clear steady state after an initial running in regime. In this study the wear rate was defined from the steady state data. The wear rate increases with the increase in applied load which may be due to the increase in the contact area between pin and disk. At $200 \mathrm{~m}$ the wear rate is higher which corresponds to the sliding distance right after the running in regime, where the slope is more pronounced specially for the greater load curves. For lower loads it is possible to notice a trend in the wear rate becoming constant. However, for higher loads a longer sliding distance might be necessary to verify this behavior. Wang et. $\mathrm{al}^{36}$ shows that the $\mathrm{Zr}$-based BMG tested for bearings rollers application has twice of the wear resistance of GCr15 steel when rubbed against brass plates under a $30 \mathrm{~N}$ normal load.
The specific wear rate $(\mathrm{k}=\mathrm{V} /(\mathrm{S} . \mathrm{N}))$ is quoted in terms of wear volume $(\mathrm{V})$ per unit load $(\mathrm{N})$ per unit sliding distance $(S)^{35}$. Figure 8 shows the specific wear rate for plates and pins as a function of sliding distance at various loads. An average value of $\mathrm{V}$ was used for each load. The specific wear rate tends to become more stable as the sliding distance increases for $10.0 \mathrm{~N}$ and $20.4 \mathrm{~N}$ loads. However, for $38.2 \mathrm{~N}$, there is an almost linear specific wear rate decrease with increasing sliding distance. This is a sign of that longer sliding distance was necessary to achieve the stable behavior. The maximum wear can be seen for pins at $38.2 \mathrm{~N}$ load whereas the minimum wear occurs for pins at $10.0 \mathrm{~N}$, showing that the specific wear rate is more pronounced for the pins than for the plates.

Table 3 shows the average wear track width and pins scar diameter $(\Delta \mathrm{d})$ for each applied load. An example of the parts used for this measurement can be observed in Figure 9 and Figure 10, where is noticeable that wear track width increases according to the load increases, as well as, the pin scar diameter. The relation between $\Delta \mathrm{d}$ and the pin diameter $(\mathrm{D}=3 \mathrm{~mm})$ shows the volume loss in the hemispheric tip of the pin which is an indicative of adhesive wear. The data presented confirmed the predominance of adhesive wear mechanism.

Figure 9 shows one plate wear morphology for each applied load in two different magnifications, where it is possible to see a section of the wear track on the left, and a fraction of the same image with higher magnification highlighting the wear mechanisms on the right. For the three different loads, most of the area exhibits adhesive wear characteristics. From the images on the left is possible to observe that the number of grooves decreases while the load increases, and from the load of $10.0 \mathrm{~N}$ to the load of $20.4 \mathrm{~N}$, the grooves seems to be larger and deeper, the same behavior reported by Zhong et. al. ${ }^{31}$. When the load increases to $38.2 \mathrm{~N}$, the grooves are not so visible, maybe because the pins had worn all the hemispherical tip during the test and the grooves generated by ploughing and/or abrasive wear had been flattened by the flat surface of the pin along all its diameter. On the other hand, the peeling off regions seams to increase and the detached debris appear to be pilled-up in the wear track, what can be seen in the imagens on the right. Some grooves observed in Figure 9B and Figure 9D might be caused by abrasive wear. Localized tribopair oxidation due to local heating and high contact pressure can lead to formation of oxide debris that can be harder than the BMG itself causing abrasive wear. $\mathrm{Fu}$ et. al. ${ }^{32}$ when studying wear between Zr-based BMG parts mention that plastic deformation could exposes the material fresh surface to the ambient environment, and the chemically active elements contained in the material ( $\mathrm{Zr}$ and Ti) forms a thin oxide layer quickly. During continuing plastic deformation, the thin layer of oxide is broken and mixed with unoxidized BMG. According to Zong et al. ${ }^{31}$ when the load increases, regions of abrasive wear became unusual and almost unnoticed as can be seen in Figure 9F.

Figure 10 shows the worn surface of the pins for different loads in two different magnifications. It is possible to notice that the hemispherical pin tip was not completely worn out, and the worn area is smaller for $10.0 \mathrm{~N}$ load (Figure 10A) than for $20.4 \mathrm{~N}$ load (Figure 10C). For the 


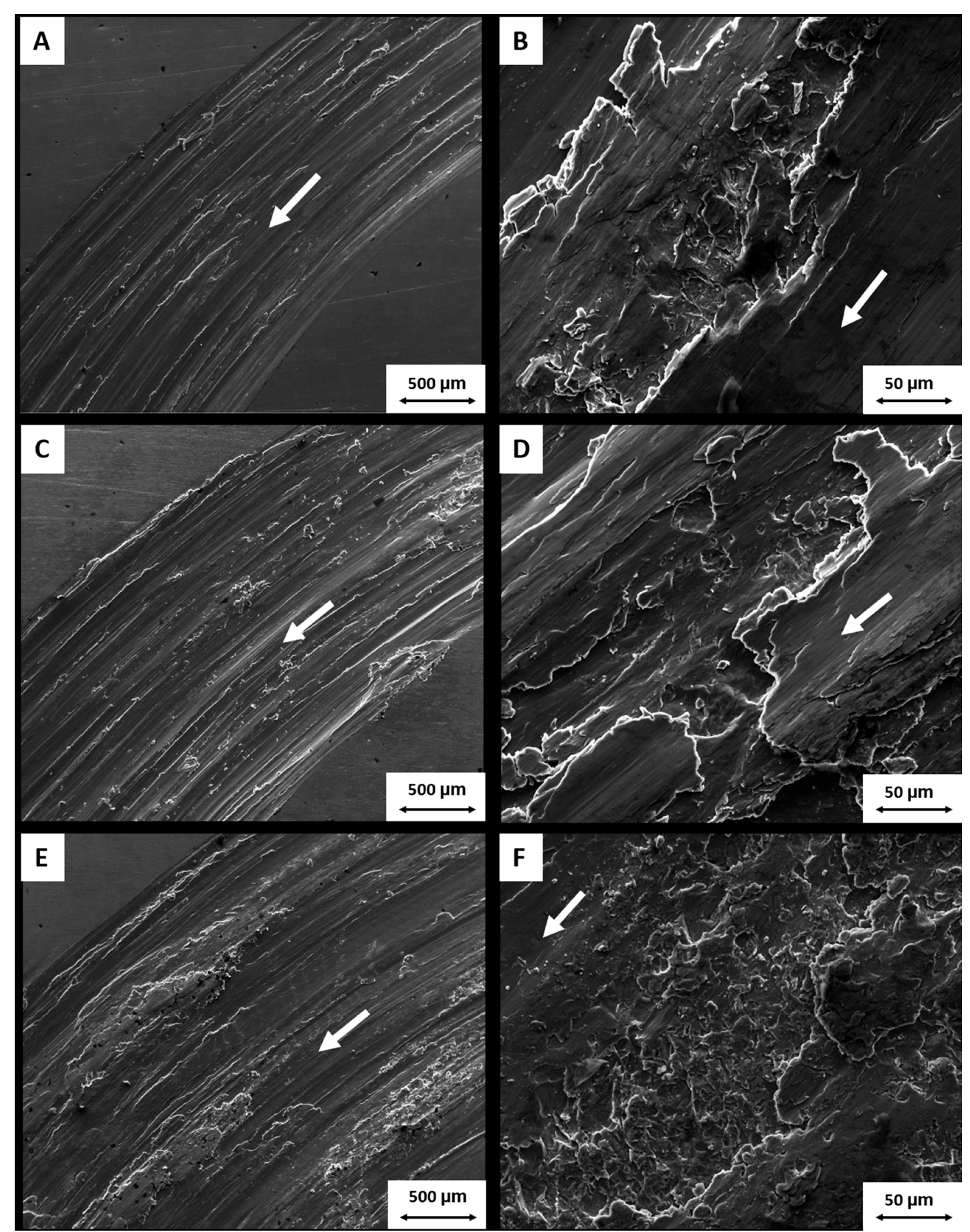

Figure 9. SEM images of BMG plates wear tracks at 100x and 1000x magnifications for applied loads of (A, B) 10.0 N, (C, D) 20.4 N, and $(\mathrm{E}, \mathrm{F}) 38.2 \mathrm{~N}$. The arrow indicates the sliding direction.

load of $38.2 \mathrm{~N}$ (Figure 10E) all the tip of the pin was worn out, and no regions of abrasive wear are observed, predominating the pilled-up material characteristic of the adhesive wear. At the loads of $10.0 \mathrm{~N}$ (Figure 10B) and $20.4 \mathrm{~N}$ (Figure 10D) there is a predominance of adhesive wear characterized by the presence of peel-off and micro-cracks. As the applied normal load increases, the micro-cracks become more visible and new micro-cracks appears after a large amount of piled-up materials was peeled-off ${ }^{31}$. This behavior can be noticed comparing the increase of micro-cracks for test under $10.0 \mathrm{~N}$ and $20.4 \mathrm{~N}$. At $38.2 \mathrm{~N}$ load the pin seams to have a big amount of pilled-up material due to the higher wear rate and some peel-off regions.

Thus, both the pins and plate surfaces exhibit a similar behavior according to the load variation. 


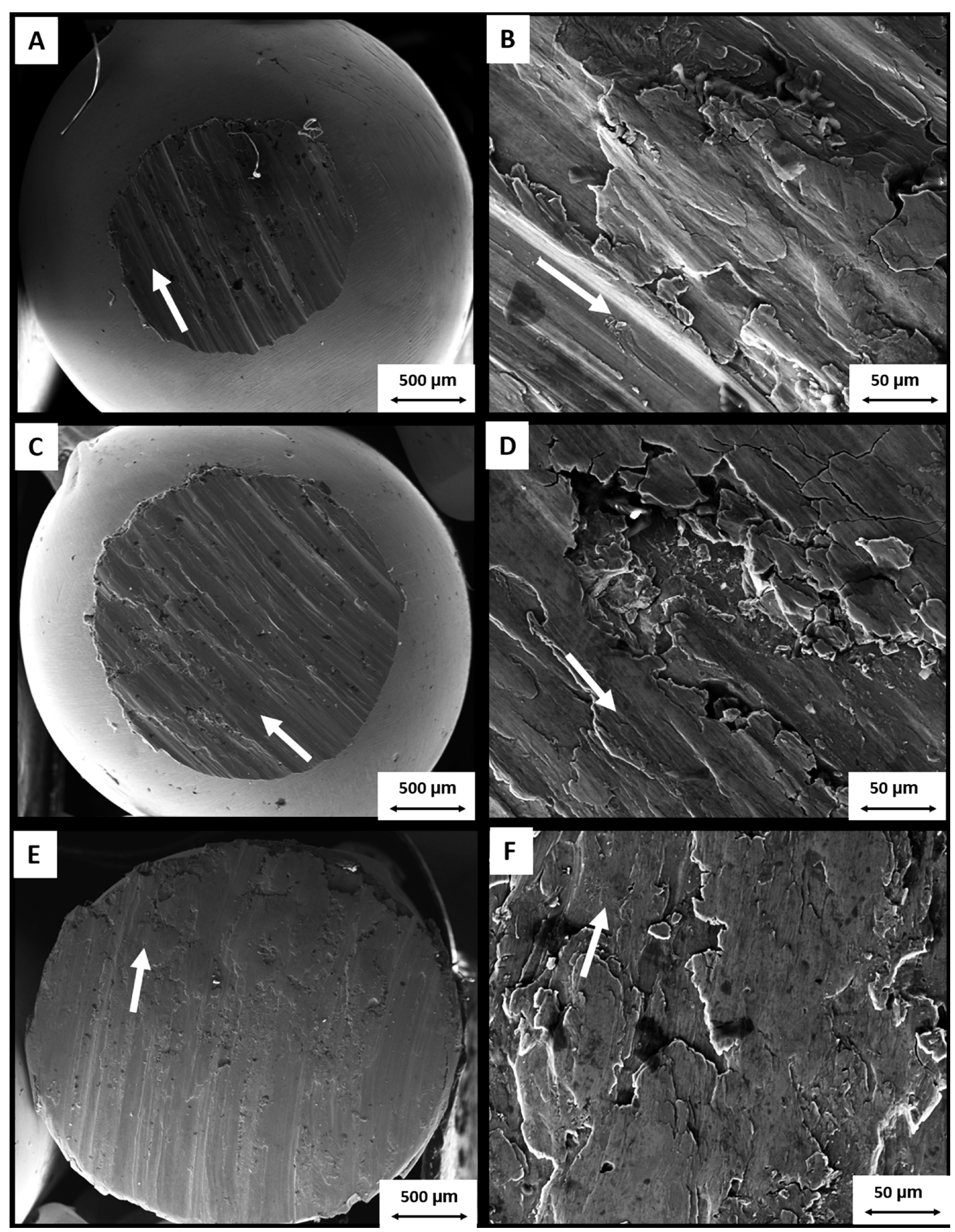

Figure 10. SEM images of BMG pins scar at 100x and 1000x magnifications for the applied loads of (A, B) 10.0 N, (C, D) 20.4 N, and (E, F) $38.2 \mathrm{~N}$. The arrow indicates the sliding direction.

\section{Conclusions}

This paper has investigated the friction and wear behavior of BMG Vitreloy-105 sliding against itself. Three different loads were applied to check the wear resistance of the material. The major conclusions are as follows:

1. XRD analysis revealed no microstructural changes after the wear tests for none of the loads applied in this study.
2. Wear rate increases with increasing the load due to higher contact area between pin and disk.

3. The wear resistance of BMGs correlates with their hardness. The pins undergone more pronounced wear mass loss possibly due to higher localized heating than the plate surface which can cause an decrease on the material hardness.

4. Average COF decreases according to load increase which can be caused by the pilled-up debris in the 
wear track covering the groves and making the surface smoother.

5. Wear mechanisms of BMG pins and plates changed from abrasive to adhesive for higher loads, and the later wear mechanism was found to be dominant under all applied loads.

6. Based on other works and considering the friction coefficient and mass loss, the results demonstrated similar wear resistance of Vitreloy-105 alloy when compared to other materials with the same application, especially the Vitreloy-1. In comparison with some crystalline metallic materials, Vitreloy-105 BMG alloy showed similar or better tribological properties when tested with a pin-on-disk geometry, in air, and without lubrication, what can make feasible the use of this alloy for some real applications.

\section{Acknowledgments}

The authors acknowledge the assistance provided by Technological Institute of Aeronautics - ITA, Center of Competence in Manufacturing - CCM in carring out the tribological tests.

\section{References}

1. Yang M, Liu X, Wu YD, Wang H, Wang J, Ruan H, et al. Elastic modulus change and its relation with glass-forming ability and plasticity in bulk metallic glasses. Scr Mater. 2019;161:62-5.

2. Dong Y, Wunderlich R, Biskupek J, Cao QP, Wang XD, Zhang DX, et al. Co content effect on elastic strain limit in $\mathrm{ZrCuNiAlCo}$ bulk metallic glasses. Scr Mater. 2017;137:94-9.

3. Si JJ, Wang T, Wu YD, Cai YH, Chen XH, Wang WY, Hui XD. Cr-based bulk metallic glasses with ultrahigh hardness. Appl. Phys. Lett, 2015;106(25):251905.

4. Jiang JZ, Hofmann D, Jarvis DJ, Fecht HJ. Low-density highstrength bulk metallic glasses and their composites: A Review. Adv Eng Mater. 2015;17(6):761-80.

5. Souza CAC, Ribeiro DV, Kiminami CS. Corrosion resistance of Fe-Cr-based amorphous alloys: an overview. J Non-Cryst Solids. 2016;442:56-66.

6. Xu T, Pang S, Li H, Zhang T. Corrosion resistant Cr-based bulk metallic glasses with high strength and hardness. J Non-Cryst Solids. 2015;410:20-5.

7. Louzguine-Luzgin DV, Ito M, Ketov SV, Trifonov AS, Jiang J, Chen CL, et al. Exceptionally high nanoscale wear resistance of a Cu47Zr45A18 metallic glass with native and artificially grown oxide. Intermetallics. 2018;93:312-7.

8. Kuriakose S, Patowari PK, Bhatt J. Machinability study of Zr$\mathrm{Cu}$-Ti metallic glass by micro hole drilling using micro-USM. J Mater Process Technol. 2017;240:42-51.

9. Kruzic JJ. Bulk metallic glasses as structural materials: a review. Adv Eng Mater. 2016;18(8):1308-31.

10. Khun NW, Yu H, Chong ZZ, Tian P, Tian Y, Tor SB, et al. Mechanical and tribological properties of Zr-based bulk metallic glass for sports applications. Mater Des. 2016;92:667-73.

11. Li TH, Wong PC, Chang SF, Tsai PH, Jang JSC, Huang JC. Biocompatibility study on Ni-free Ti-based and Zr-based bulk metallic glasses. Mater Sci Eng C. 2017;75:1-6.

12. Hofmann DC, Andersen LM, Kolodziejska J, Roberts SN, Borgonia JP, Johnson WL, Kennett A. Optimizing bulk metallic glasses for robust, highly wear-resistant gears. Adv Eng Mater, 2017;19(1):1600541.

13. Hofmann DC, Polit-Casillas R, Roberts SN, Borgonia JP, Dillon RP, Hilgemann E, et al. Castable bulk metallic glass strain wave gears: towards decreasing the cost of high-performance robotics. Sci Rep. 2016;6:37773.
14. Rahaman ML, Zhang LC, Ruan HH. Understanding the friction and wear mechanisms of bulk metallic glass under contact sliding. Wear. 2013;304(1-2):43-8.

15. Blau PJ. Friction and wear of a Zr-based amorphous metal alloy under dry and lubricated conditions. Wear. 2001;250(1-12):431-34.

16. Bakkal M. Sliding tribological characteristics of Zr-based bulk metallic glass under lubricated conditions. Intermetallics. 2010;18(6):1251-3.

17. Liu Y, Yitian Z, Xuekun L, Liu Z. Wear behavior of a Zr-based bulk metallic glass and its composites. J Alloys Compd. 2010;503(1):13844.

18. Jiang F, Qu J, Fan G, Jiang W, Qiao D, Freels MW, et al. Tribological Studies of a Zr-Based Glass-Forming Alloy with Different States. Adv Eng Mater. 2009;11(11):925-31.

19. Hong WU, Baker I, Yong LIU, Wu XL. Dry sliding tribological behavior of Zr-based bulk metallic glass. Trans Nonferrous Met Soc China. 2012;22(3):585-9.

20. Rahaman ML, Zhang LC, Ruan HH. Understanding the friction and wear mechanisms of bulk metallic glass under contact sliding. Wear, 2013;304(1-2):43-8.

21. Parlar Z, Bakkal M, Shih AJ. Sliding tribological characteristics of Zr-based bulk metallic glass. Intermetallics. 2008;16(1):34-41.

22. Li H, Fan C, Tao K, Choo H, Liaw PK. Compressive behavior of a Zr-Based metallic glass at cryogenic temperatures. Adv Mater. 2006;18(6):752-4.

23. Campos Neto NDD, Paula WMD, Pereira FS, Parrish CJ, Oliveira MFD. Influence of small content elements additions on the glass forming ability of Zr-based bulk metallic glasses alloys. Mat Res. 2018;21(6):1-6.

24. Ueura K, Kiyosawa Y, Kurogi JI, Kanai S, Miyaba H, Maniwa $\mathrm{K}$, et al. Tribological aspects of a strain wave gearing system with specific reference to its space application. Proc Inst Mech Eng, Part J J Eng Tribol. 2008;222(8):1051-61.

25. Zhong H, Chen J, Dai LY, Yue Y, Wang BA, Zhang XY, et al. Effect of counterpart material on the tribological properties of Zr-based bulk metallic glass under relatively heavy loads. Wear. 2016;346:22-8.

26. Joo SH, Pi DH, Guo J, Kato H, Lee S, Kim HS. Enhanced wear resistivity of a $\mathrm{Zr}$-based bulk metallic glass processed by highpressure torsion under reciprocating dry conditions. Met Mater Int. 2016;22(3):383-90.

27. Verougstraete V, Danzeisen R, BurzlaffA, Oller A, Heim K, Vetter $\mathrm{D}$, et al. Mechanisms underlying toxicity of complex inorganic materials. In: Verougstraete V. Risk management of complex inorganic materials. London, UK: Academic Press; 2018. p. 27-54.

28. ASTM International. ASTM G99-0: Standard test method for wear testing with a pin-on-disk apparatus. Materials Park, OH: ASTM; 2010.

29. Neto NC, Soares C, Pereira FS, Bergamaschi V, Antonio SG, Kaufman MJ, et al. Glass forming ability and continuous-coolingtransformation (CCT) diagrams of Vitreloy 105 as function of cooling rate and oxygen concentration. J Non-Cryst Solids. 2020;528:119762.

30. Fu XY, Rigney DA. Tribological characteristics of Zr 41.2 Ti 13.8 $\mathrm{Cu} 12.5 \mathrm{Ni} 10.0 \mathrm{Be} 22.5$ bulk metallic glass. MRS Symp. Proc. 1998;554(1998):437-42.

31. Zhong H, Chen J, Dai L, Yue Y, Zhang Z, Zhang X, et al. Tribological behaviors of Zr-based bulk metallic glass versus Zr-based bulk metallic glass under relative heavy loads. Intermetallics. 2015;65:8893.

32. Fu XY, Kasai T, Falk ML, Rigney DA. Sliding behavior of metallic glass: Part I. Experimental investigations. Wear. 2001, 250(1-12):409-419.

33. Rabinowicz E. Friction and wear of materials. New York: Wiley \& Sons. Inc.; 1995.

34. Stachowiak GW. Wear: materials, mechanisms and practice. New York: Wiley \& Sons. Inc; 2006.

35. Greer AL, Rutherford KL, Hutchings IM. Wear resistance of amorphous alloys and related materials. Int Mater Rev. 2002;47(2):87-112.

36. Wang DH, Xie SH, Yang HP, Qian HX, Zeng XR. Wear behaviors of three typical bulk metallic glasses in bearing applications. Metals (Basel). 2018;8(12):1005. 